(c) 2018, Elsevier. Licensed under the Creative Commons AttributionNonCommercial-NoDerivatives 4.0 International

http://creativecommons.org/licenses/by-nc-nd/4 .0/

Bailey Peptides antidiabetic vR1 2017

\title{
Glucose-lowering therapies in type 2 diabetes: opportunities and challenges for peptides
}

\section{Clifford J. Bailey}

School of Life and Health Sciences, Aston University, Birmingham, UK

The author declares no specific conflict of interest for this review, but discloses research support, honoraria, and ad hoc advisory activities associated with several pharmaceutical companies interested in the treatment of diabetes and obesity.

Correspondence to:

Professor Clifford J. Bailey,

School of Life and Health Sciences,

Aston University,

Birmingham B4 7ET, UK

c.j.bailey@aston.ac.uk

Tel. +44 (0) 1212043898

4983 words total 


\begin{abstract}
This overview considers the opportunities and challenges that face the use of glucoregulatory peptides to treat type 2 diabetes. New insulin analogues and formulations are being developed with pharmacokinetic properties to speed-up or prolong transfer from a subcutaneous injection site to the target tissues, or to selectively favour effects on the liver. Alternative routes of insulin administration continue to attract attention, and advances in the integration of glucose monitoring with insulin pump devices are improving miniaturised 'closed loop' artificial pancreas systems. Proof of concept has been established for noncellular glucose-responsive insulin delivery ('smart insulins') to release insulin from implants or circulating depots in proportion to circulating glucose. The many peptides involved in blood glucose control offer diverse therapeutic opportunities. Exploitation of multiple selected receptor targets using constructs of hybrid and chimeric peptides, especially those based on glucagon and gastrointestinal hormones, has gained much credence from initial preclinical studies. Peptide templates identified from comparative endocrine studies have also provided valuable insights in this respect and indicated novel approaches to address associated conditions such as obesity and infections at the same time. Nevertheless, there are many challenges to the use of therapeutic peptides that impose on every step in the complex pathway from design and testing through to making a fully characterised therapeutic product, and optimising administration, tissue targeting and degradation. Stability of peptides and immunological uncertainties of novel structures require particular consideration as well as the need to avoid over-reduction of blood glucose into hypoglycaemia.
\end{abstract}

\title{
Introduction
}

Hormonal peptides play a decisive role in the control of blood glucose homeostasis from the activation of feeding behaviour and the intestinal digestion of carbohydrates through to the storage, mobilisation and utilisation of glucose as a vital source of energy. Blood glucose concentrations are normally maintained within a narrow range of 4-9 $\mathrm{mmol} / \mathrm{L}$, due mostly to peptide hormones that balance fluctuations in the prandial supply and tissue storage of nutrients with the varied demands of normal metabolism and the extremes of exercise and fasting. Excess glucose accumulates in the liver and muscle as glycogen or is converted to triglyceride in adipose tissue, and the liberation of these 
nutrient stores is highly regulated. Low blood glucose concentrations (hypoglycaemia) below about 3 $\mathrm{mmol} / \mathrm{L}$ cause symptoms of neuroglycopenia and concentrations below $2 \mathrm{mmol} / \mathrm{L}$ can be fatal. Conversely, exposure to high circulating glucose concentrations (hyperglycaemia) above about 10-12 $\mathrm{mmol} / \mathrm{L}$ causes glucosuria, osmotic diuresis and risk of dehydration, while persistent hyperglycaemia (diabetes) causes glucotoxic damage to the endothelium of capillaries which typically manifests as nephropathy and retinopathy as well as nerve cell damage responsible for neuropathies. Glucotoxic damage to the endothelium in large vessels also contributes to the long-term increased risk of cardiovascular disease in type 2 diabetes [1].

The persistent hyperglycaemia of diabetes is predominantly due to defects in the secretion and/or action of insulin, but many other regulatory peptides are intimately involved, especially with type 2 diabetes. Lack of insulin and impaired insulin action (insulin resistance) deprive major insulinsensitive tissues such as active skeletal muscle of adequate glucose. Inadequate insulin is also responsible for unrestrained output of glucose by the liver and fatty acids released from adipose tissue, resulting in the elevated concentrations of these nutrients in the circulation. Beyond disruption of insulin-glucose dynamics, altered production, secretion and activity of many other peptide hormones contribute to the metabolic disturbances and the pathogenic sequelae in diabetic states. These include other pancreatic hormones and regulatory peptides of the alimentary tract, other neuroendocrine glands, adipose tissue and further peptide-secreting tissues [Table 1]. This chapter will focus on the breadth of opportunities and the challenging constraints for peptide therapies in the management of hyperglycaemia in type 2 diabetes.

\section{Glycaemic control in type 2 diabetes}

Whereas type 1 diabetes is necessarily dominated by the insulinopenic effect of near total autoimmune beta cell destruction and the need for life-preserving delivery of insulin replacement therapy, type 2 diabetes attracts a wider variety of therapeutic approaches to address its multiple causes and its variable progression (Figures 1 and 2) [2,3]. These approaches include treatments to improve insulin action or other manoeuvres to reduce demands on insulin secretion or increase beta cell function. They also include stimulation of insulin secretion and more physiological delivery of exogenous insulin, as well as suppression of hormones that normally raise blood glucose concentrations. The underlying purpose of these approaches is to reinstate glycaemic control to as near normal as practicable, safe and comfortable for the patient in order to relieve acute symptoms, minimise the impact of glucotoxic microvascular complications, and lessen the compounding detrimental effects of insulin resistance, glucotoxicity, lipotoxicity and other metabolic aberrations on cardiovascular risk in type 2 diabetes. 
When evaluating strategies to improve glycaemic control it is appreciated that the severity of insulin resistance in type 2 diabetes can often require several times the normal physiological amount of insulin to achieve near normal blood glucose concentrations. Although interventions to raise insulin concentrations are necessary when insulin concentrations are severely depleted, stimulating insulin secretion is not always possible or ideal because high concentrations of insulin promote the down regulation of insulin receptors and accentuate lesions in the post-receptor pathways of insulin action $[4,5]$. Also, excess insulin causes weight gain, mostly as extra adipose deposition which further aggravates insulin resistance, and over insulinisation can precipitate episodes of hypoglycaemia. Hence alternatives to insulin can be advantageous in the treatment of type 2 diabetes to reduce insulin requirements, and combinations of differently acting agents can be used to address different facets of the disease. Thus the many different peptides involved in glucose regulation provide potential targets and templates for a breadth of therapeutic approaches.

\section{Opportunities to improve insulin delivery}

The administration of insulin in advanced insulinopenic states of type 2 diabetes is usually initiated by subcutaneous injection of once-daily or twice-daily long-acting or intermediate-acting insulin to provide an approximately consistent basal concentration. This may be supplemented if required with additional (bolus) amounts of a short-acting or rapid-acting insulin to coincide with meals, similar to the normal pattern of endogenous insulin secretion [6]. A recent refinement to create an even faster rapid-acting insulin (Fiasp) is a formulation that includes nicotinamide to improve absorption and arginine as a stabilizing agent. Regarding longer acting insulins, refinements under investigation to prolong circulating half-life include linkage to polyethylene glycol (PEGylation) and modified fatty acid linkage to albumin, enabling more consistent day profiles of plasma insulin with more predictable glycaemic control and fewer 'hypos'. As patents on existing insulin analogues expire, copies of these insulins (biosimilar insulins) are set to emerge. Abasaglar is a recently introduced copy of the long-acting insulin glargine. It is pertinent to note that although biosimilars are intended to be similar to existing products but they are unlikely to be exact replicas: the manufacturing process involves living organisms which can vary, the isolation and formulation processes may be slightly different and the final products are therefore unlikely to be identical to their reference products. Hence, switching between products may require dose adjustment $[7,8]$.

For the last thirty years the strength of insulin preparations has been unified to 100 units per $\mathrm{ml}$, where 1 unit of insulin glucose-lowering activity is equivalent to $37.5 \mathrm{ug}(6 \mathrm{nmol})$ of pure natural human insulin. This conformity was introduced to reduce the risk of medication errors which occurred when insulin was available in various different strengths, the only exception being a 500 units per $\mathrm{ml}$ strength for special high-dose requiring circumstances. Now we are seeing a re-emergence of 
different strengths of insulins at 100, 200,300, 400 and 500 units per ml. In most western countries insulin is now largely delivered with pen injectors where an exact dose is selected using a digital dial, but use of an ordinary syringe to extract the dose from a vial of insulin is still undertaken by healthcare professionals in hospitals and by patients in many parts of the world, requiring extra caution against dosage errors.

To reduce the frequency of basal insulin injections from once or twice daily to once weekly or once monthly, several possible very slow release insulin depots are being tested. These include a subcutaneous depot of microspheres containing 5-kDa PEGylated human insulin lasting for a week and a heat-sensitive PEG-based subcutaneously injected biodegradable polymer that forms a gel at body temp and releases insulin from a depot of chitosan-zinc-insulin over a month [8,9].

\section{Tissue-selective insulin}

A particular limitation of subcutaneously administered insulin by injections and pumps is that it does not target the liver with higher concentrations than the periphery as occurs under physiological circumstances with the release of insulin from the pancreas into the portal circulation. To provide proportionally more insulin to the liver than to muscle or adipose tissue, insulin analogues have been linked to selected sizes of PEG (eg insulin lispro coupled to a 20-kDa PEG). While this prolongs circulation time it also enables the molecules to penetrate the wide fenestrations of the sinusoidal endothelium in the liver but reduces access to muscles and fat [10]. Although a preferential hepatic action was achieved this particular molecule has not progressed in development.

\section{Alternatives to injections}

To overcome the inconvenience of bolus meal-time injections, inhaled insulins (eg Exubera and Afrezza) have been well developed to administration of small quantities of insulin for rapid absorption. However, low bioavailability, high cost and concerns about dose accuracy and possible adverse effects on the lungs have resulted in discontinuation [11]. However, a buccal spray preparation of insulin (Oral-Lyn) is available in some countries to conveniently deliver small prandial doses of insulin, but development of nasal sprays have been limited by variable bioavailability and damage to the nasal epithelium by absorption enhancers [12].

Oral delivery is possible for gradual administration of a basal insulin, and many different types of oral preparations have been evaluated, but bioavailability is generally low and often inconsistent.

Approaches include various forms of encapsulation from liposomes to nanoparticles, and the use of absorption enhancers such as sodium-chlorosalicyloyl-aminobutyrate (CNAB). The difficulties are well rehearsed, notably peptidase degradation and $\mathrm{pH}$ sensitivities, as well as transfer from lumen to venous or lymphatic drainage, the latter running the gauntlet of Peyer's patches and slow transit to the 
circulation [12-14]. Sometimes forgotten is the potential for unabsorbed bioactive insulin to generate unwanted effects in the colon [15].

\section{Pumps and implants}

An account of insulin pump technologies is beyond the scope of this review, but it is appreciated that controlled subcutaneous or intravenous delivery of insulin by programmable pumps with manual over-ride is well established [16]. Various closed-loop versions that take advantage of advances in glucose monitoring and dose-calculation software to automatically adjust insulin dose have been successfully trialled in type 1 diabetes $[17,18]$. Discretely concealed patch pumps attached to the skin are gaining application for open- and closed-loop systems: the patch comprises a small refillable or replaceable insulin reservoir and a small remotely controlled pump to deliver the insulin subcutaneously via a cannula hidden beneath $[19,20]$.

A review of live tissue approaches to insulin delivery using isolated islets, cultured beta-cells, differentiated insulin-secreting stem cells and gene therapy manipulations is also beyond the bounds of the present article and these aspects are recently comprehensively reviewed elsewhere [21-23]. An interesting novel approach demonstrated in diabetic mice has used an implant of optogenetically engineered insulin-secreting cells that are activated by implanted light-emitting diodes and controlled via a smartphone in response to signals from a glucose monitor and remote computer [24]. This illustrates the potential of bioengineering to harness advances in electrical and communication technologies together with genetic and implantation technologies to control the delivery of peptides from live sources. Of note are anecdotal comments that reliance on entirely automated technological solutions to deliver insulin can deskill patients who then find it difficult to take over if the technology fails.

\section{Smart insulins}

Several glucose-responsive insulin delivery systems (so-called smart insulins) have been developed to release insulin from an implanted depot, circulating macromolecule or nanoparticles in proportion to the circulating concentration of glucose by a direct chemical reaction. Boronc acid derivatives have been particularly useful in this respect because glucose binds across two boronate molecules to form a bis-boronate complex. So if insulin is loaded into a hydrogel containing large polymers to which boronates are attached, glucose will deform the polymer or increase cross-links and squeeze out the insulin in proportion to the amount of glucose. Alternatively, if the insulin is linked to boronic acidcontaining polymers, this can be displaced by glucose $[25,26]$. Indeed, insulin analogues linked to 
boronic acid deivatives via a fatty acid chain provided a glucose-responsive mechanism to release insulin which achieved more effective glycaemic control than unlinked insulin analogues in diabetic mice [27].

Another approach with proof of principle in preclinical studies has utilised glucose oxidase within layers of polymers that coat implanted insulin-loaded vesicles. Interaction with glucose causes the glucose oxidase to produce glucono-lactone which alters the integrity of the polymers and releases insulin [28] . Similarly, injectable microgels containing glucose oxidase and loaded with insulin in a $\mathrm{pH}$-responsive chitosan matrix will swell and release insulin in proportion to the protonation as glucose is oxidised [29]. A glucose oxidase-based insulin release system has also been incorporated into a transdermal patch with microneedles that penetrate subcutaneously. The microneedles deliver polymeric vesicles incorporating glucose oxidase and insulin. The insulin is released through an effect of hydrogen peroxide produced by the interaction of glucose with the glucose oxidase [30].

\section{Mixtures of peptides}

The inclusion of more than one peptide within a single injection dates from the late 1950s when premix insulins were introduced. A biphasic action profile of these mixtures is achieved using an acetate buffer suitable for a protamine-insulin with no excess of zinc (intermediate-acting time course) and an excess of free insulin (soluble rapid-acting or short-acting) which remains separate. Given as a single subcutaneous injection the rapid- or short-acting component provides a prompt rise of insulin concentrations to address the blood glucose excursion from an immediate meal, while the intermediate-acting component provides basal insulinisation for a longer period between meals. Different proportions of rapid- or short-acting free insulin together with intermediate-acting protamine-insulin are available, and it is pertinent to note the transAtlantic nomenclature discrepancy where the short-acting component is written first in Europe (ie, a 30/70 mix refers to 30\% short-acting and $70 \%$ intermediate-acting), whereas in North America the long-acting component is written first. Although still used extensively in some regions of the globe, premix insulins are being superseded by basal-bolus regimens in which a daily injection of a long-acting insulin is accompanied by administration of rapid- or short-acting insulin with dose adjustment to suit timing, composition and size of individual meals [6].

In some regions there has been limited specialist use of a combination of the amylin analogue pramlintide with insulin to improve prandial glycamic control by slowing gastric emptying, increasing satiety, assisting weight control and reducing glucagon [31]. However the pramlintide and insulin are not mixed together in the same syringe [32]. Preparing stable mixtures of peptides with different physicochemical properties, particularly different solubility characteristics, poses a considerable challenge. However, mixtures of insulin with a GLP-1 receptor agonist (GLP-1RA) have been 
developed and used effectively in patients with type 2 diabetes [33]. These two different classes of agents offer complementary actions, such that the GLP-1RA can provide additional glucose-lowering by potentiating glucose-dependent insulin secretion and suppressing glucagon secretion. The satiety effect of GLP-1RAs can also off-set the weight gain associated with insulin therapy [34].

IDegLira is a fixed-ratio combination of the long-acting insulin degludec with the GLP-1RA liraglutide in the ratio 100 units insulin with $3.6 \mathrm{mg} / \mathrm{ml}$ liraglutide. The combination is delivered via a pen device as a single daily subcutaneous injection titrated in the same way as for insulin. In a 1 year clinical trial in type 2 diabetes, IDegLira reduced HbA1c (by 1.84\%) more than degludec alone (by $1.40 \%$ ) or liraglutide alone (by $1.21 \%$ ). IDegLira also prevented the weight gain associated with the insulin component alone, and achieved a greater reduction of $\mathrm{HbA1c}$ with a lower daily amount of insulin (39 units with IDegLira versus 62 units with degludec) and fewer episodes of hypoglycaemia [35]. Fixed-ratio combinations of the basal insulin glargine with the GLP-1RA lixisenatide (IGlarLixi) have also been developed in ratios of 2 or 3 units of glargine to 1 ug of lixisenatide. Compared with insulin glargine alone, IGlarLixi produced greater reductions of $\mathrm{HbA1c}$ with lower daily amounts of insulin, lower risk of hypoglycaemia and without weight gain in type 2 diabetes patients, similarly to IDegLira $[36,37]$.

\section{Hybrid and chimeric peptides}

Preclinical studies have provided evidence that separate injections of GLP-1 and other selected glucoregulatory peptides can assist metabolic control, and this has prompted the development of hybrid molecules [38\}. For example, GLP-1 has been linked with gastrin to improve beta-cell mass, or with glucagon to improve energy expenditure and satiety [39,40]. However, if a combination of two peptides with complementary actions can be used in a single injection, what are the opportunities for mixtures of three or more peptides? Three differently acting oral (non-peptide) glucose-lowering agents or one or two oral agents with one or two injectable agents (insulin and/or a GLP-1RA) are sometimes used in advanced insulin resistant and insulinopenic stages of type 2 diabetes [2].

The prospect of improving the management of type 2 diabetes with multiple peptides in the same injection has encouraged the development of chimeric peptides, and a dual-action chimeric peptide with an intermixed sequence of GLP-1 and GIP has been shown to exert glucose-lowering and insulin releasing effects in obese-diabetic rodent models, cynomolgus monkeys and humans [41]. Recently the chimeric concept has been taken from two to three agonist actions with the construction of novel amino acid sequences that enable interaction with GLP-1 plus GIP plus glucagon [42, 43]. For example a DPP-4 resistant GLP-1 analogue which was modified to activate receptors for GLP-1, GIP and glucagon ([dA(2)]GLP-1/GcG) lowered plasma glucose in insulin resistant obese-diabetic (ob/ob) mice and high fat-fed mice, the latter also showing weight reduction [42]. Another triple-acting 
chimeric peptide with agonist effects at the GLP-1, GIP and glucagon receptors, and without crossreactivity at other related receptors has been reported to reduce body weight, improve glycaemic control, decrease excess liver fat, supress food intake and increase energy expenditure in rodent models [43]. Thus, in addition to enhancing the incretin effect and improving glycaemic control, chimeric peptides can be structured to address the obesity that frequently accompanies type 2 diabetes and contributes to the insulin resistance and other co-morbidities [44]. The balance of activities requires the glucose-lowering effect of GLP-1 to predominate over the potential for glucagon to raise blood glucose, while effects mediated through receptors for both of these peptide can reduce caloric intake and glucagon can improve energy expenditure. Although GIP promotes nutrient-mediated insulin release it can also enhance glucagon secretion and exert variable effects on body composition in different metabolic circumstances, emphasising the importance of achieving an appropriate balance between the three receptor interactions.

\section{Depot GLP-1}

Limited adherence to peptide injection regimens may significantly compromise their potential benefits [45]. Whereas the detrimental effects of missed insulin injections are soon manifest in poor health, reduced adherence to administration schedules for GLP-1RAs are less easily recognised, and longer acting may help to obviate adherence issues associated with frequent injections. The protracted effects of GLP-1RAs reduce hyperglycaemia without causing hypoglycaemia, facilitate weight reduction, appear to protect pancreatic beta cells from apoptosis and may reduce CV risk in type 2 diabetes $[46,47]$. A depot technology giving continuous delivery of exenatide is a match stick-sized subcutaneously implanted miniature osmotic pump (ITCA 650) which maintains therapeutic concentrations and sustains glycaemic efficacy with $\mathrm{HbA} 1 \mathrm{c}$ reductions of $>1.4 \%(15 \mathrm{mmol} / \mathrm{mol})$ for up to 2 years $[48,49]$. The device is readily implanted and removed intact, and although $19 \%$ of patients initially developed anti-exenatide antibodies, the antibody titres subsequently declined and were only measurable in $2.8 \%$ of patients by 2 years and did not appear to be directed against the active site of exenatide. A particularly interesting feature of the device is the storage of sufficient exenatide into such a small volume and to remain biologically patent during implantation for 2 years. It is anticipated that the device could soon become available for routine clinical use and should provide an opportunity to improve adherence by obviating repeated injections.

An early concept type of GLP-1RA depot uses a subcutaneously injected soluble fusion protein ELP (elastin-like-polypeptide) to form a gel at body temperature [50]. The ELP is linked to oligomers of a GLP-1 analogue with an Ala8 to Gly substitution for DPP-4 resistance and a Gly22 to Glu substitution to stabilize the $\alpha$-helix. Monomers are separated by a Gly-Ala dipeptide added to the $\mathrm{N}$ terminus and an Arg added at the C-terminus. This enables monomers to be released by local 
arginine-specific proteases and then activated by DPP-4 (dipepidyl peptidase-4) which cleaves the Nterminal Gly-Ala to leave the active GLP-1 analogue. Thus, this so-called POD (protease operated depot) takes advantage of endogenous DPP-4 to isolate the active GLP-1 analogue without causing GLP-1 degradation, and its ability to maintain release of the GLP-1 has been demonstrated over 5days in mice.

\section{Other peptides}

Beyond the examples considered above, several further gluco-regulatory peptides exert effects that could be harnessed therapeutically to improve glycaemic and related disturbances in type 2 diabetes [51]. These are considered in detail in subsequent articles in this issue of Peptides, but it is appropriate to comment briefly here [Table 1].

The relative hyperglucagonaemia of type 2 diabetes presents a particular therapeutic conundrum because the production of glucagon can be suppressed and the action interrupted, but compensatory mechanisms are then invoked and the counter-regulatory response of glucagon during hypoglycaemia can be vital $[52,53]$. That said, glucagon promotes appetite control and energy expenditure and provides a convenient foundation sequence of amino acids for chimeric constructs [42]. Although GLP-1 and GIP can be exploited therapeutically to modulate glycaemic control, additional hormones from the alimentary tract have shown therapeutic potential in early clinical studies. Oxyntomodululin has attracted interest because it interacts with GLP-1 and glucagon receptors to reduce feeding, increase energy expenditure and reduce body weight while lowering blood glucose in type 2 diabetes $[54,55]$. The satiety and weight-reducing effects of peptide YY, ghrelin antagonists and cholecystokinin analogues are being examined for the treatment of obesity [56-58], and emerging evidence from bariatric procedures may reveal additional intestinal peptides with therapeutic potential in type 2 diabetes [59].

Adipose tissue continues to provide peptides with gluco-regulatory effects that could be utilised for therapeutic purposes. The appetite-suppressing, weight-lowering and metabolic effects of metraleptin have been explored extensively but have therapeutic limitations due to escalating leptin resistance [60]. The weight-lowering and insulin-sensitising properties of adiponectin are attractive, but given the physicochemical properties of adiponectin, non-peptide modulation of adiponectin receptors may be more practicable for therapeutic purposes in type 2 diabetes [61]. Many other adipokines, including resistin, retinol-binding proteim- 4 , omentin, visfatin and apelin have been noted as possible targets for future peptide therapeutics in type 2 diabetes [51], and fibroblast growth factor 21 (FGF21) derived from adipose tissue and other organs has entered clinical study [62]. Peptides from other sources, such as fetuin from liver and irisin from muscle are emerging as prospective therapeutic targets, and there remains untapped potential to examine the activities of brain neurotransmitter 
peptides. Comparative endocrinology has already informed diabetes therapeutics with a novel peptide (exendin-4 from the gila monster, Heloderma suspectum), and identified many other new peptides with gluco-regulatory potential, indicating the diversity of leads from which peptide therapies can arise $[63,64]$.

\section{Peptide opportunities}

As illustrated by the foregoing examples, peptides offer a spectrum of potential therapeutic opportunities to improve blood glucose control in type 2 diabetes. Because many peptides are known to contribute to normal glucose homeostasis, and disturbances in the secretion and/or action of several of these peptides are pivotal in the development and progression of type 2 diabetes, a selection of peptide-dependent targets is recognised. Peptides are highly selective in their actions at defined receptors and can be structurally modified for desired adjustments to their pharmacokinetic and pharmacodynamic properties. When administered as natural replacements they are generally well tolerated and have good safety profiles when used judiciously with attention to dose, timing, and consideration of co-morbidities and potential drug interactions.

Commercial production methods which mostly include recombinant DNA introduced into bacterial or fungal cultures, are economically viable with predictable purity, consistency and sterility during storage, distribution and usage by healthcare professionals and patient self-administration. Many different devices facilitate measured and comfortable administration, including dose-dialled pen devices with timing records and alerts as well as pumps and skin patches. Formulations for enteral and inhaled delivery have received extensive investigation, and although unsuccessful to date they remain interesting opportunities. Smart molecules that are self-regulating offer an exciting potential alternative to cell-based therapies. Advancing knowledge of the secondary and tertiary structures of peptide hormones and their receptor binding sites has fostered burgeoning libraries of structures with defined receptor binding and activity profiles which focus opportunities to construct peptides (eg chimeric) with selected epitopes for particular functions. As capability grows to amalgamate multiple therapies into a single peptide it is anticipated that future medicines will be able to take advantage of insights from proteomics, metabolomics and pharmacogenomics to tailor such peptides to individual needs. Combining epitopes of multiple peptide agonists into a single designer peptide offers the potential to simultaneously address a variety of therapeutic targets to suit the individual patient and to circumvent many of the physico-chemical differences that detract from the combination of individual peptides in a single injection.

\section{Peptide challenges}


Significant challenges continue to face the therapeutic application of peptide including their design, production and administration, through to their distribution within the body and their degradation. Ongoing basic research into structure-function events at the cellular level, especially interactions of peptides with receptors and the control of receptor function and post-receptor pathways, should inform the future design of hormonal peptides to achieve particular physiological effects. A recent example of the importance of this research is the crystallographic determination of the binding of insulin at its receptor to initiate the conformational adjustments that enable the intracellular extension of the receptor to operate as a kinase enzyme [65,66]. This has opened a new avenue of exploration into the design of molecules to mimic all or part of this process, which (peptide enthusiasts may see ironically) as a vision that could enable smaller non-peptide molecules to duplicate some of the therapeutic functions of insulin [67]. Initial research with non-peptide agonists at the GLP-1 and adiponectin receptors, and non-peptide glucagon receptor antagonists have also shown promise, but this approach is still in its infancy [51]. While non-peptide molecules are more easily produced and administered, they do not offer the possibility to construct multifunctional molecules that exert a selected variety of effects at several different receptors.

Since the production of large peptides usually involves living organisms and multiple steps for isolation, purification, characterisation and formulation, there are very considerable commercial challenges to provide a consistent quality product with guaranteed sterility and an adequate shelf-life. This in turn is reflected in availability and price, fuelling economic deliberations over cost versus value, even when lives are at stake. Various physicochemical complexities continue to impinge, most notably stability before and after administration.

With regard to administration, most of the obstacles that confront the use of peptides in diabetes apply to peptide therapies in general, but diabetes imposes extra difficulties due to the tight constraints on blood glucose concentrations and the rapidity and extent of fluctuations in glucose supply and demand. Although the timing and choice of dose for any therapy can be paramount, an ability to stop or reverse an adverse effect and prevent an over-effect remains a continual challenge for the treatment of diabetes. Avoiding hypos and other safety requirements, including the minimisation of CV risk must take account of the prospect that a therapy might be required for many years and maybe for life. Moreover, use of some peptides may be restricted by the comorbidities of diabetes, particularly impaired kidney and liver functions which are prevalent in diabetes and alter the pharmacokinetics of peptide therapies. Type 2 diabetes patients often require a large number of medications which increases the risk of drug interactions: for example delayed gastric emptying with a GLP-1RA can alter the time course of oral medications. 
Although further formulations and analogues with different periods of onset and durations of action will doubtless continue to address the time-sensitive nature of glycaemic control, basal insulin and GLP-1RAs can be delivered without rapid fluctuations: the former provide an approximately constant non-prandial low concentration of insulin and the latter can reduce hyperglycaemia without precipitating hypoglycaemia during inter-prandial periods. Hence these peptides lend themselves to slow release formulations, for example by attachment to albumin, or transdermal or oral administration. However, methods to improve oral delivery, avoiding proteolysis and accommodating vast changes of $\mathrm{pH}$ within the GI tract remain a formidable task. Current methods to enhance bioavailability with absorption enhancers, such as used for the gastric uptake of semaglutide, require periods with an empty stomach which can interrupt normal feeding patterns. Excess active peptides in the lymphatic drainage of the gut and incomplete intestinal absorption resulting in active peptides in the colon also raise questions and cautions.

Immunogenicity applies particularly to analogues of natural peptides and especially to 'designer' constructs with much reduced homology compared to native structures. Antibody production can vary greatly and unpredictably between individuals, and the risk of a catastrophic acute reaction must be appreciated. However, overall this review provides evidence that with appropriate benefit-risk discretion, further advances in peptide therapeutics offer the potential to address a breadth of metabolic and associated morbidities in type 2 diabetes.

\section{References}

1. Gerich JE. Physiology of glucose homeostasis. Diabetes Obesity Metab 2000, 2, 345-50.

2. Bailey CJ. The current drug treatment landscape for diabetes and perspectives for the future. Clin Pharmacol Therap 2015, 98, 170-84 
3. Tahrani AA, Barnett AH, Bailey CJ. Pharmacology and therapeutic implications of current drugs for type 2 diabetes mellitus. Nature Reviews Endocrinology 2016, 12, 566-92.

4. DeFronzo R A. From the triumvirate to the ominous octet: a new paradigm for the treatment of type 2 diabetes mellitus. Diabetes 2009, 58, 773-95.

5. Kahn SE, Cooper ME, Del Prato S. Pathophysiology and treatment of type 2 diabetes: perspectives on the past, present, and future. Lancet 2014, 383:1068-83.

6. Home P, Riddle M, Cefalu WT, Bailey CJ, Bretzel RG, Del Prato S, Leroith D, Schernthaner G, van Gaal L, Raz I. Insulin therapy in people with type 2 diabetes: opportunities and challenges? Diabetes Care 2014, 37, 1499-508.

7. Setty SG, Crasto W, Jarvis J, Khunti K, Davies MJ. New insulins and newer insulin regimens: a review of their role in improving glycaemic control in patients with diabetes. Postgrad Med J 2016, 92, 1085. doi.org/10.1136/postgradmedj-2015-133716

8. Cahn A, Miccoli R, Dardano A, Del Prato S. New forms of insulin and insulin therapies for the treatment of type 2 diabetes. Lancet Diabetes Endocrinol 2015, 3, 638-52.

9. Oak M, Singh J. Chitosan-zinc-insulin complex incorporated thermosensitive polymer for controlled delivery of basal insulin in vivo. J Controlled Release 2012, 163, 145-53.

10. Madsbad S. LY2605541-A preferential hepato-specific insulin analogue. Diabetes 2014, 63: 390-2.

11. Pittas AG. Inhaled insulin therapy in diabetes mellitus. Uptodate Diabetes 2017. https://www.uptodate.com/contents/inhaled-insulin-therapy-in-diabetes-mellitus Accessed 29 September 2017

12. Shah RB, Patel M, maahs DM, Shah VN. Insulin delivery methods: Past, present and future. Int J Pharmaceutical Investigation 2016, 6, 1-9.

13. Zijlstra E, Heinemann L, Plum-Mörschel L. Oral insulin reloaded: a structured approach. J Diabetes Sci Technol 2014, 8: 458-65.

14. Zaykov AN, Mayer JP, DiMarchi RD. Pursuit of a perfect insulin. Nat Rev Drug Discov.2016; 15: 425-39.

15. Yin S, Bai H, Jing D. Insulin therapy and colorectal cancer risk among type 2 diabetes mellitus patients: a systemic review and meta-analysis. Diagnostic Pathology 2014, 9:91

https://doi.org/10.1186/1746-1596-9-91 Accessed 29 September 2017 
16. McAdams BH, Rizvi AA. An overview of insulin pumps and glucose sensors for the generalist. J Clin Med. 2016, 5: 5. doi: 10.3390/jcm5010005 Accessed 29 September 2017

17. Thabit H, Tauschmann M, Allen JM, Leelarathna L Hartnell,S et al. Home use of an artificial beta cell in type 1 diabetes. N Engl J Med 2015; 373: 2129-40

18. Haider A, Rabasa-Lhoret R, Legault L, Lovblom LE et al. Single- and dual-hormone artificial pancreas for overnight glucose control in type 1 diabetes. J Clin Endocrinol Metab 101: $214-23$, 2016.

19. Anhalt H, Bohannon NJV. Insulin Patch Pumps: Their Development and Future in Closed-Loop Systems. Diabetes Technol Ther, 2010, 12 (suppl 1): S51-8.

20. Blauw H, Keith-Hynes P, Koops R, DeVries JH. A Review of Safety and Design Requirements of the Artificial Pancreas. Ann Biomed Eng 2016; 44: 3158-72.

21. Avogaro A, Fadini GP. Stem cell therapy in diabetes. In Textbook of diabetes, $5^{\text {th }}$ edition, Holt RIG, Cockram CS, Flyvbjerg A, Goldstein BJ. John Wiley, Chichester, 2017, pp 1012—6.

22. Koh A, SeniorPE, Shapiro AMJ. Islet transplantation. In Textbook of diabetes, 5th edition, Holt RIG, Cockram CS, Flyvbjerg A, Goldstein BJ. John Wiley, Chichester, 2017, pp 1017—28.

23. Haurigot V, Jimenez V, Bosch F. Gene therapy for diabetes. In Textbook of diabetes, 5th edition, Holt RIG, Cockram CS, Flyvbjerg A, Goldstein BJ. John Wiley, Chichester, 2017, pp 102937.

24. Shao J, Xue S, Yu G, Yu Y et al. Smartphone-controlled optogenetically engineered cells enable semiautomatic glucose homeostasis in diabetic mice. Science Translational Medicine 2017: 9, 387, eaal2298. Doi. 10.1126/scitranslmed.aal2298

25. Guan Y, Zhang Y. Boronic acid-containing hydrogels: synthesis and their applications. Chem Soc Rev 2013, 42, 8106-21.

26. Ma R, Shi L. Phenylboronic acid-based glucose-responsive polymeric nanoparticles: synthesis and applications in drug delivery. Polym Chem 2014, 5, 1503-18.

27. Chou DHC, Webbera MJ, Tanga BC, Lin AB et al. Glucose-responsive insulin activity by covalent modification with aliphatic phenylboronic acid conjugates. Proc Natl Acad Sci, USA 2015, $112,2401-6$. 
28. Xu C, Lei C, Huang L, Zhang J, Zhang $\mathrm{H}$ et al. Glucose-responsive nanosystem mimicking the physiological insulin secretion via an enzyme-polymer layer-by-layer coating strategy. Chem Mater 2017, 29, 7725-32.

29. Gu Z, Dang TT, Ma M, Tang BC, et al. Glucose-responsive microgels integrated with enzyme nanocapsules for closed-loop insulin delivery ACS Nano 2013, 7, 6758-66.

30. $\mathrm{Hu} \mathrm{X}, \mathrm{Yu}$ J, Qian C, Lu Y, et al. H2O2-responsive vesicles Integrated with transcutaneous patches for glucose-mediated insulin delivery. ACS Nano 2017, 11, 613-20.

31. Pullman J, Darsow T, Frias JP. Pramlintide in the Management of Insulin-Using Patients with Type 2 and Type 1 Diabetes. Vasc Health Risk Manag 2006, 2: 203-12.

32. Riddle MC, Yuen KCJ, de Bruin TW, Herrmann K et al. Fixed ratio dosing of pramlintide with regular insulin before a standard meal in patients with type 1 diabetes. Diabetes Obesity Metab 2015, 17: $904-7$.

33. Vora J. Combining incretin-based therapies with insulin: realizing the potential in type 2 diabetes. Diabetes Care 2013, 36 (suppl 2): S226-32.

34. Nauck MA, Meier JJ. Incretin mimetics and insulin - closing the gap to normoglycaemia. Nature Rev Endocrinol 2016, 12, 689-690

35. Gough SC, Bode BW, Woo VC, Rodbard HW et al, One-year efficacy and safety of a fixed combination of insulin degludec and liraglutide in patients with type 2 diabetes: results of a 26-week extension to a 26-week main trial. Diabetes Obes Metab 2015, 17, 965-73.

36. Rosenstock J, Aronson R, grunberger G, Hanefeld M et al. Benefits of LixiLan, a titratable fixedratio combination of insulin glargine plus lixisenatide, versus insulin glargine and lixisenatide monocomponents in type 2 diabetes inadequately controlled on oral agents: the LixiLan-O randomized trial. Diabetes Care 2016, 39: 2026-35.

37. Aroda VR, Rosenstock J, Wysham C, Unger J et al. Efficacy and safety of LixiLan, a titratable fixed-ratio combination of insulin glargine plus lixisenatide in type 2 diabetes inadequately controlled on basal insulin and metformin: the LixiLan-L randomized trial. Diabetes Care 2016, 39: 1972-80.

38. Sadry SA, Drucker DJ. Emerging combinatorial hormone therapies for the treatment of obesity and T2DM. Nature Rev Endocrinol 2013, 9, 425-33. 
39. Fosgerau K, Jessen L, Lind Tolborg J, Osterlund T, et al. The novel GLP-1-gastrin dual agonist, ZP3022, increases beta-cell mass and prevents diabetes in db/db mice. Diabetes Obesity Metab 2013, $15,62-71$.

40. Fosgerau K, Hoffmann T. Peptide therapeutics: current status and future directions. Drug Discovery Today 2015, 20, 122-8.

41. Finan B, Ma T, Ottaway N, Müller TD, et al, Unimolecular dual incretins maximize metabolic benefits in rodents, monkeys, and humans. Sci Transl Med 2013, 30; 209ra151. doi: 10.1126/scitranslmed.3007218.

42. Gault VA, Bhat VK, Irwin N, Flatt PR. A novel glucagon-like peptide-1 (GLP-1)/glucagon hybrid peptide with triple-acting agonist activity at glucose-dependent insulinotropic polypeptide, GLP-1, and glucagon receptors and therapeutic potential in high fat-fed mice. J Biol Chem 2013, 288, 35581-91.

43. Finan B, Yang B, Ottaway N, Smiley DL et al. A rationally designed monomeric peptide triagonist corrects obesity and diabetes in rodents. Nature Medicine 2015, 21, 27-36.

44. Scheen AJ, Van Gaal LF. Combating the dual burden: therapeutic targeting of common pathways in obesity and type 2 diabetes. Lancet Diabetes Endocrinol 2014, 2, 911-22.

45. Bailey CJ, Kodack M. Patient adherence to medication requirements for therapy of type 2 diabetes. Int J Clin Pract 2011, 65, 314-22.

46. Henry RR, Klein EJ, Han J, Iqgal N. Efficacy and tolerability of exenatide once weekly over 6 years in patients with type 2 diabetes: an uncontrolled open-label extension of the DURATION-1 study. Diabetes Technol Ther 2016, 18, 677-86.

47. Marso SP, Daniels GH, Brown-Frandsen K, Kristensen P et al. Liraglutide and Cardiovascular Outcomes in Type 2 Diabetes. N Engl J Med 2016; 375:311-22.

48. Henry RR, Rosenstock J, Logan D, Alessi T, et al. A randomized trial of continuous subcutaneous delivery of exenatide by ITCA 650 vs. twice daily exenatide injections in metformintreated type 2 diabetes. Diabetes Care 2013; 36: 2559-65

49. Henry RR, Rosenstock J, Logan D, Alessi T, et al. Continuous subcutaneous delivery of exenatide via ITCA 650 leads to sustained glycemic control and weight loss for 48 weeks in metformin-treated subjects with type 2 diabetes. J Diabetes Complications 2014, 28, 393-98. 
50. Amiram M, Luginbuhl KM, Li X, Feinglos MN, Chilkotia A. Injectable protease-operated depots of glucagon-like peptide-1 provide extended and tunable glucose control. Proc Natl Acad Sci USA 2013, 110, 2792-97.

51. Bailey CJ, Tahrani A, Barnett AH. Future glucose-lowering drugs for type 2 diabetes. Lancet Diabetes Endocrinology 2016, 4, 350-9.

52. Christensen M, Bagger JI, Vilsboll T, Knop FK. The alpha-cell as target for type 2 diabetes therapy. Rev Diabet Studies 2011; 8: 369-81.

53. Sammons MF, Lee ECY. Recent progress in the development of small-molecule glucagon receptor antagonists. Bioorg Med Chem Lett 2015; 25: 4057-64.

54. Pocai A. Action and therapeutic potential of oxyntomodulin. Mol Metab 2014, 3: 241-51.

55. Holst JJ. Oxyntomodulin actions and role in diabetes. Peptides 2018 in press

56. De Silva A, Bloom SR. Gut Hormones and Appetite Control: A Focus on PYY and GLP-1 as Therapeutic Targets in Obesity. Gut Liver 2012, 6: 10-20.

57. Verchere CB. Peptide therapeutics for weight loss: preventing plasma pancreatic polypeptide proteolysis. Endocrinology 2017, 158, 1567-68

58. Delporte C. Recent advances in potential clinical application of ghrelin in obesity. J Obesity 2012, 535624. http://dx.doi.org/10.1155/2012/535624 Accessed 30 September 2017

59. Rubino F, Nathan DM, Eckel RH, Schauer PR, et al, Metabolic surgery in the treatment algorithm for type 2 diabetes: a joint statement by International Diabetes Organizations. Diabetes Care 2016, 39: 861-77.

60. Moon HS, Matarese G, Brennan AM, Chamberland JP et al. Efficacy of metreleptin in obese patients with type 2 diabetes: cellular and molecular pathways underlying leptin tolerance. Diabetes 2011, 60:1647-56.

61. Achari AE, Jain SK. Adiponectin, a therapeutic target for obesity, diabetes, and endothelial dysfunction. Int J Mol Sci 2017, 18, E1321. doi: 10.3390/ijms18061321.

62. Stowski MZ. Impact of FGF21 on glycemic control. Horm Mol Biol Clin Investig 2017, 30, 0001. doi: 10.1515/hmbci-2017-0001

63. Conlon JM, Mechkarska M, Abdel-Wahab YH, Flatt PR. Peptides from frog skin with potential for development into agents for type 2 diabetes therapy. Peptides 2018, in press. 
64. O'Harte FPM, Ng MT, Lynch AM, Conlon JM, Flatt PR. Dogfish glucagon analogues counter hyperglycaemia and enhance both insulin secretion and action in diet-induced obese diabetic mice. Diab Obes Metab 2016, 18, 1013-24

65. Menting JG, Whittaker J, Margetts MB, Whittaker LJ et al. How insulin engages its primary binding site on the insulin receptor. Nature 2013, 493, 241-45

66. Menting JG, Gajewiak J, MacRaild CA, Hung-Chieh D et al. A minimized human insulinreceptor-binding motif revealed in a Conus geographus venom insulin. Nature Structural \& Molecular Biology 2016, 23, 916-20

67. Qiang G, Xue S, Yang JJ, Du G et al. Identification of a small molecular insulin receptor agonist with potent antidiabetes activity. Diabetes 2014, 63:1394-409. 


\section{Figure 1.}

Type 2 diabetes is a progressive and variable disease in which substantial disturbances of insulin action and secretion have usually occurred before diagnosis. The disease arises through multiple genetic factors (eg ethnic, body composition, expression levels of enzymes and transporters affecting nutrient metabolism) which interact with multiple environmental factors (eg quality and quantity of the diet, physical exercise, co-morbid conditions and medications), which accounts for the heterogeneity of the disease. Male gender, increased parity and gestational diabetes amongst women, family history of diabetes and obesity are known to increase the risk of diabetes. An early feature of the pathogenic process is a gradual reduction of insulin action (insulin resistance) that is initially compensated by increased insulin secretion. When the increased insulin concentrations are unable to fully compensate for the insulin resistance there is a rise in postprandial glucose concentrations and later fasting glucose concentrations referred to as impaired glucose tolerance (IGT) and impaired fasting glucose (IFG) respectively. This is associated with a decline or delay in the initial (first phase) secretion of insulin in response to a prandial rise in blood glucose, although the second phase of insulin secretion is usually accentuated. The usual rhythm of insulin secretion is lost and increased proportions of proinsulin and incompletely processed proinsulin, which have less biological activity than insulin, are released by the 'stressed' beta cells. Excess adiposity aggravates insulin resistance through altered lipid supply and the release of pro-inflammatory adipokines. If, in presence of insulin resistance, the secretory function of the 'stressed' beta cell population declines, the condition of IGT/IFG progresses into type 2 diabetes, and a continued deterioration of beta cell function and mass gives rise to escalating hyperglycaemia. Concurrent changes to the secretion and action of other gluco-regulatory peptides contribute to the rising hyperglycaemia, notably a relative hyperglucagonaemia and impaired action of GLP-1.

\section{Figure 2.}

Inadequate blood glucose control in type 2 diabetes involves disturbances of many gluco-regulatory peptide hormones, including insulin, glucagon, incretins and other gastro-intestinal peptides, adipokines and neuro-endocrine peptides. These provide a variety of different therapeutic targets through which current agents address the hyperglycaemia. All treatment strategies are underpinned by lifestyle measures, notably diet, exercise and general health education, and pharmacological therapies are selected on an individualised basis to be commensurate with the changing circumstances of the patient as the disease progresses. Metformin, which is usually the first-line drug choice in type 2 diabetes counters insulin resistance, reducing hepatic glucose production and facilitating glucose utilisation. Sulfonylureas and meglitinides stimulate insulin secretion by pancreatic beta cells. 
Dipeptidyl peptidase-4 (DPP-4) inhibitors slow the degradation of the main incretin hormones glucagon-like peptide-1 (GLP-1) and glucose-dependent insulinotropic polypeptide (GIP) thereby enhancing their effects. GLP-1 receptor agonists (GLP-1RAs) are GLP-1 analogues which mimic the effects of GLP-1 to potentiate glucose-dependent insulin secretion, reduce glucagon secretion by pancreatic alpha cells, delay gastric emptying and exert a satiety effect. Sodium-glucose cotransporter-2 (SGLT2) inhibitors reduce glucose reabsorption by the kidney and increase loss of excess glucose in the urine. Pioglitazone is a thiazolidinedione peroxisome proliferator-activated receptor-gamma (PPAR $\square$ ) activator that promotes differentiation of insulin-sensitive adipocytes and improves insulin sensitivity. Acarbose inhibits intestinal alpha-glucosidase enzymes which slows the final stages of carbohydrate digestion, slowing the entry of glucose into the circulation. In some countries (not Europe) glucose-lowering indications are approved for the bile acid sequestrant colesevelam, which may increase GLP-1 secretion from intestinal L-cells, and the dopamine receptor agonist bromocriptine, which triggers neural pathways to reduce hepatic glucose output. The amylin analogue pramlintide is also available in some regions as a supplement to insulin therapy to increase satiety, slow gastric emptying and reduce glucagon secretion. Insulin is the essential therapy for type 1 diabetes and usually the default therapy for advanced stages of type 2 diabetes when other agents are no longer adequately effective. Insulin facilitates glucose uptake, storage and metabolism by muscle, reduces glucose production by liver, reduces lipolytic release of fatty acids from adipose tissue and exerts many other metabolic and cell-differentiating effects essential for life.

Figure 3

Concepts for 'smart insulins' using polymers containing boronic acid derivatives (eg, phenylboronic acid) embedded within a gel containing insulin. A. Glucose binds two boronates to produce a glucosebis-boronate complex. B. Glucose-bis-boronate complexes deform the polymer with increased cross links that squeeze out insulin from the gel in proportion to the glucose concentration. C. Alternatively if insulin is linked to boronate-containing polymers, the insulin can be displaced by interaction with glucose, releasing insulin in proportion to the glucose concentration. Based on refs 25 and 26. 
Table 1. Gluco-regulatory peptides with established or potential therapeutic use in the management of hyperglycaemia in type 2 diabetes. $\uparrow$ increase; $\downarrow$ decrease

\begin{tabular}{|c|c|c|}
\hline Peptide hormone & Main gluco-regulatory effects & Type 2 diabetes therapeutic potential \\
\hline \multicolumn{3}{|l|}{ Pancreas } \\
\hline Insulin & $\begin{array}{l}\downarrow \text { Hepatic glucose output } \\
\uparrow \text { Peripheral glucose uptake and } \\
\text { utilization } \\
\downarrow \text { Lipolysis } \\
\uparrow \text { Protein anabolism } \\
\uparrow \text { Growth and differentiation }\end{array}$ & $\begin{array}{l}\text { Lowers blood glucose but can cause } \\
\text { hypoglycaemia. Default glucose- } \\
\text { lowering therapy in severely } \\
\text { insulinopenic type } 2 \text { diabetes. Many } \\
\text { available analogues, formulations and } \\
\text { delivery systems. Extensive } \\
\text { developments in progress }\end{array}$ \\
\hline Glucagon & $\begin{array}{l}\uparrow \text { Hepatic glucose output } \\
\uparrow \text { Energy expenditure } \\
\uparrow \text { Satiety }\end{array}$ & $\begin{array}{l}\text { Raises blood glucose: key counter- } \\
\text { regulatory effect. Relative } \\
\text { hyperglucagonaemia in type } 2 \\
\text { diabetes is potential therapeutic } \\
\text { target. }\end{array}$ \\
\hline Somatostatin & $\begin{array}{l}\downarrow \text { Glucagon and insulin secretion } \\
\downarrow \text { Growth hormone secretion } \\
\text { Many other neuro-endocrine roles, } \\
\text { especially in GI tract }\end{array}$ & $\begin{array}{l}\text { Analogues used therapeutically to } \\
\text { treat excess GH, but suppression of } \\
\text { insulin reduces suitability for type } 2 \\
\text { diabetes }\end{array}$ \\
\hline $\begin{array}{l}\text { Pancreatic } \\
\text { polypeptide }\end{array}$ & $\begin{array}{l}\downarrow \text { Food intake } \\
\text { Various GI effects }\end{array}$ & Possible value in treatment of obesity \\
\hline Amylin (IAPP) & $\begin{array}{l}\uparrow \text { Satiety } \\
\downarrow \text { Gastric emptying } \\
\downarrow \text { Glucagon secretion }\end{array}$ & $\begin{array}{l}\text { Analogue (pramlintide) available in } \\
\text { some regions for use with insulin: } \\
\text { assists glucose lowering and weight } \\
\text { loss }\end{array}$ \\
\hline \multicolumn{3}{|l|}{ Alimentary tract } \\
\hline GLP-1 & $\begin{array}{l}\uparrow \uparrow \text { Nutrient-induced insulin secretion } \\
\downarrow \text { Glucagon secretion } \\
\downarrow \text { Gastric emptying } \\
\uparrow \text { Satiety and } \downarrow \text { body weight } \\
\text { Emerging CV and neuroprotective } \\
\text { effects }\end{array}$ & $\begin{array}{l}\text { Established blood glucose-lowering } \\
\text { therapy in overweight and obese type } \\
2 \text { diabetes, especially with metformin } \\
\text { and insulin. Fixed ratio combinations } \\
\text { with insulin }\end{array}$ \\
\hline GIP & $\begin{array}{l}\downarrow \text { Gastric acid secretion } \\
\uparrow \text { Nutrient-induced insulin secretion } \\
\uparrow \text { Glucagon secretion } \\
\text { Emerging roles in adipogenesis and }\end{array}$ & $\begin{array}{l}\text { Research into potential therapeutic } \\
\text { role: effects of agonists and } \\
\text { antagonists vary with physiological } \\
\text { state. Potential therapeutic role }\end{array}$ \\
\hline
\end{tabular}




\begin{tabular}{|c|c|c|}
\hline & bone remodelling & $\begin{array}{l}\text { supported by bariatric procedures that } \\
\text { reduce contact of food with } \\
\text { duodenum }\end{array}$ \\
\hline Peptide YY & $\begin{array}{l}\downarrow \text { Gastric emptying } \\
\uparrow \text { Satiety and } \downarrow \text { body weight }\end{array}$ & Potential anti-obesity therapy \\
\hline Oxyntomodulin & $\begin{array}{l}\uparrow \text { Nutrient-induced insulin secretion } \\
\downarrow \text { Gastric emptying } \\
\uparrow \text { Energy expenditure } \\
\uparrow \text { Satiety and } \downarrow \text { body weight } \\
\text { Overall effects on glucagon? } \\
\text { Emerging effects on liver and adipose } \\
\text { tissue }\end{array}$ & $\begin{array}{l}\text { Potential therapy for type } 2 \text { diabetes. } \\
\text { Agonist at receptors for GLP-1 and } \\
\text { glucagon: uncertain balance of } \\
\text { glucose lowering effect via GLP-1R } \\
\text { versus glucose-raising effect via } \\
\text { glucagon receptor. Possible } \downarrow \text { ghrelin, } \\
\uparrow \text { adiponectin and } \uparrow \text { FGF } 21\end{array}$ \\
\hline Cholecystokinin & $\begin{array}{l}\uparrow \text { Gall bladder contraction } \\
\uparrow \text { Pancreatic digestive enzymes } \\
\uparrow \text { Satiety } \\
\downarrow \text { Gastric emptying } \\
\text { Various neural effects }\end{array}$ & $\begin{array}{l}\text { Fragments and analogues that } \\
\text { preferentially promote satiety } \\
\text { considered for therapeutic purposes. } \\
\text { Possible effect on islet beta-cell } \\
\text { growth }\end{array}$ \\
\hline Gastrin & $\begin{array}{l}\uparrow \text { Gastric acid secretion } \\
\uparrow \text { Gastric motility }\end{array}$ & $\begin{array}{l}\text { Possible effect on islet beta-cell } \\
\text { growth }\end{array}$ \\
\hline Secretin & $\uparrow$ Pancreatic juice and enzymes & Possible islet effects unclear \\
\hline Ghrelin & $\begin{array}{l}\uparrow \text { Appetite } \\
\uparrow \text { Adipogenesis } \\
\uparrow \text { Growth hormone }\end{array}$ & $\begin{array}{l}\text { May decrease insulin secretion. } \\
\text { Research into potential therapeutic } \\
\text { role of antagonists }\end{array}$ \\
\hline Obestatin & $\begin{array}{l}\downarrow \text { Appetite } \\
\text { Emerging metabolic effects }\end{array}$ & $\begin{array}{l}\text { Therapeutic interest in possible effect } \\
\text { on islet beta-cell growth and } \\
\text { antagonism of ghrelin }\end{array}$ \\
\hline \multicolumn{3}{|l|}{ Adipose tissue } \\
\hline Adiponectin & $\begin{array}{l}\uparrow \text { Insulin sensitivity } \\
\uparrow \text { Energy expenditure } \\
\text { Various metabolic, anti-inflammatory } \\
\text { and vascular effects }\end{array}$ & $\begin{array}{l}\text { Therapeutic application of } \\
\text { adiponectin itself limited by } \\
\text { physicochemical properties, but other } \\
\text { agonists of adiponectin receptors and } \\
\text { agents to stimulate adiponectin } \\
\text { secretion being studied }\end{array}$ \\
\hline Leptin & $\begin{array}{l}\downarrow \text { Appetite and } \downarrow \text { body weight } \\
\uparrow \text { Insulin sensitivity } \\
\uparrow \text { Energy expenditure } \\
\text { Neurally mediated effects that improve } \\
\text { glucose homeostasis }\end{array}$ & $\begin{array}{l}\text { Short-term therapeutic value of } \\
\text { metraleptin to reduce body weight } \\
\text { and lower blood glucose is limited by } \\
\text { increasing leptin resistance }\end{array}$ \\
\hline Resistin & $\uparrow$ Insulin resistance ? & Target candidate for antagonism? \\
\hline Omentin & $\begin{array}{l}\uparrow \text { Insulin sensitivity } \\
\text { Emerging vascular effects ? }\end{array}$ & Target candidate for agonism? \\
\hline Visfatin & Insulin-like effects? & Possible target candidate? \\
\hline Apelin & $\begin{array}{l}\text { Emerging vascular and metabolic } \\
\text { effects }\end{array}$ & Possible target candidate? \\
\hline \multicolumn{3}{|l|}{ Liver } \\
\hline $\begin{array}{l}\text { Fibroblast growth } \\
\text { factor- } 21\end{array}$ & $\uparrow$ Insulin sensitivity & $\begin{array}{l}\text { FGF-21 resistance may occur in } \\
\text { obesity and type } 2 \text { diabetes }\end{array}$ \\
\hline $\begin{array}{l}\text { Insulin-like growth } \\
\text { factors }\end{array}$ & Weak insulin-like effects & $\begin{array}{l}\text { Assist glycaemic control if severe } \\
\text { defects of insulin receptors }\end{array}$ \\
\hline
\end{tabular}




\begin{tabular}{|l|l|l|}
\hline Fetuins & $\begin{array}{l}\text { Emerging evidence of impaired } \\
\text { glycaemic control }\end{array}$ & Possible target candidates ? \\
\hline Muscle & $\uparrow$ Energy expenditure & Possible target candidate ? \\
\hline Irisin
\end{tabular}

Other peptide or amino acid-derived hormones such as those of the hypothalamus-pituitary, thyroid and adrenal medulla are involved in gluco-regulation but are not considered here as candidates for a specific therapeutic role in the management of hyperglycaemia in type 2 diabetes. 